HISTORICAL REVIEW

\title{
History of diaphragm physiology: the achievements of Galen
}

\author{
J-Ph. Derenne*, A. Debru**, A.E. Grassino+, W.A. Whitelaw ${ }^{++}$
}

\begin{abstract}
History of diaphragm physiology: the achievements of Galen. J-Ph. Derenne, A. Debru, A.E. Grassino, W.A. Whitelaw. CERS Journals Ltd. 1995.

ABSTRACT: Galen (129-200 AD) produced a large written output which was to remain one of the major basis of clinical medicine for centuries. His contribution to respiration, reported in his own books and in those of Oribasius, was that of a chest physician and of an experimental physiologist. He described in minute details how to perform a remarkable series of experiments by which he demonstrated the anatomy and function of the respiratory muscles. He described the actions of the diaphragm and how it moves the rib cage, in a series of spinal chord sections and muscle denervations. He investigated the passive or active nature of expiration and made fine observations of lung movements through the exposed pleural space. He described the interaction between the lungs and chest wall and developed the concept of interaction between ribcage and abdominal muscles in maintaining the position of the diaphragm, showing a clear understanding of the principle that the diaphragm can move upward during an isovolume manoeuvre as long as the ribcage is allowed to expand. A skillful clinician, Galen applied his theories of the analysis of problems at the bedside, particularly in patients affected with dyspnoea which he attributed to respiratory muscle dysfunction.
\end{abstract}

Eur Respir J., 1995, 8, 154-160.

\begin{abstract}
*Service de Pneumologie, Hôpital de la Pitié-Salpétrière, Paris, France. **Université Charles de Gaulle-Lille III, Département Langues Anciennes, Villeneuve d'Ascq, France. +Université de Montreal and Meakins Christie Laboratories, Montreal, Quebec, Canada. ${ }^{++}$Dept of Medicine, University of Calgary, Calgary, Alberta, Canada.
\end{abstract}

Correspondence: J-Ph. Derenne

Service de Pneumologie

Groupe Hospitalier de la Pitié-Salpêtrière 47, boulevard de l'Hôpital

75651 Paris Cédex 13

France

Keywords: Abdomen and ribcage, diaphragm, Galen, history of medicine, theories of respiration

Received: February 91994

Accepted after revision August 201994
We remember Galen chiefly for the outdated system of elements and humors that preceded biochemistry, and for his failure to perceive the circulation of the blood. In both cases, our own concepts are so deeply rooted in modern ways of thought that it is difficult for us to appreciate his ideas and easy to underestimate his contribution. In the case of the respiratory pump, however, Galen's anatomical dissections, whole-animal experiments and clinical studies were conceived in astonishingly modern terms, were carried out very systematically, and led to conclusions that are now considered largely correct. On reading his description of them, it is easy to understand how their author gained the reputation he did, and why he dominated the field of respiratory muscle physiology from Roman times to the 17 th century.

Of the man and his life, all we know is what he wrote himself $[1,2]$, but there is little reason to doubt its truth. In the 19,000 pages of manuscript available, Galen rambles over hundreds of subjects, mixes theory, practice, anecdote and commentary, and gives away much of his own character. He loves to tell stories of his triumphs, not neglecting to emphasize the intelligence, upbringing, hard work and clever analysis that led to them. He describes his opponents with contemptuous insults, and gives many of his eminent predecessors less honour than they deserve. Singer found him "arrogant, self-centred, contentious, and a wearisome word-splitter" [3]. Reading his work may not make us love the man but does compel us to admire his brilliant and original mind, immense intellectual, ambition, inexhaustible energy, and extraordinary penchant for writing. To the advantage of medical science, fate provided him with a life of inherited ease, a stable political environment, and permanent recognition by the government - the equivalent of tenure plus a lifetime of research grants.

He was born in Pergamon in Asia Minor in 129 AD, the son of a wealthy and learned merchant. His father pushed him first in the direction of philosophy, which Galen took up with enthusiasm, but then advised him to pursue a career in medicine. Pergamon at the time held one of the Roman world's most renowned medical schools, and attracted famous physicians and teachers from all over the Mediterranean. Galen studied there from the age of 18-22 yrs, then travelled for 4 yrs to Pelops, Smyrna and Alexandria, seeking rare manuscripts and teachers to perfect his education. At $27 \mathrm{yrs}$ of age, he returned to Pergamon and began his clinical career as a "sports" medicine doctor. His first appointment was the prestigious post of physician to the gladiators, where he gained extensive experience of surgery and had many opportunities to observe injuries to the respiratory apparatus. He was proud to have greatly reduced the death rate in wounded gladiators by means of innovative 
treatments. In 162, at the age of $32 \mathrm{yrs}$, he headed for Rome, the centre of power and influence, where he spent most of the rest of his life. In 167, Marcus Aurelius summoned Galen to join him on a military expedition, and appointed him to take care of his son Commodus. Galen's library and many of his own manuscripts were destroyed in a fire in Rome in 192. He died about 210 AD.

In the capital of the empire at the time most physicians were Greek [4]. Almost all adhered to one or another specific sect, empiricist, pneumatist, methodist or rationalist; each insisting on its own approach to the theory and practice of medicine, and each drawing on a long tradition of philosophy and argument. In that era, as in ours, there was a great public interest in medicine, so that any well-educated person might expect to have some knowledge and an opinion about the various medical theories and practices. Lectures, demonstrations and debates were very public affairs, where rival physicians brought huge retinues of students for show $[4,5]$. The flavour of this contentious age comes to us through the rhetorical and polemical tone of some of the writings of Galen, who provoked the hatred of many of the sects by insisting on a rational evaluation of all medical science and therapeutics, an evaluation based on careful observation, testing of hypotheses by experiments and elaboration of a coherent theory. In voluminous writings, he summarized, evaluated and criticized the works of his rivals and predecessors, described his own prodigious experimental and clinical observations, and made a synthesis of the state of the art in his day that would remain the reference for medicine and a guide and source book for scientists beyond the Renaissance.

Galen's concept of respiration was a modification of that of the Alexandrian physiologist Erasistratus 400 yrs earlier [6]. He rejected many of the metaphysical ideas of respiration that were current at the time, but accepted the dominating force of the "innate heat" and the existence of "pneuma". Both of these concepts were abstract, complex and evolved differently in the hands of the different philosophical schools. In general, innate heat was a kind of source of warmth intimately associated with life itself. Pneuma was a vital principle that formed part of living creatures and was somehow connected with air. Galen's writings contained an extended consideration of the parallel between the innate heat and a flame. Such a comparison suggests that Galen anticipated the modern understanding that respiration and combustion were similar chemical processes, but the similarity is more in the words and images than in the ideas. In fact, for Galen the air did not really provide extra fuel for the flame. It only provided a mechanism to regulate the combustion of the substrate by guiding the flame in an upward or downward direction and by adjusting the degree of warmth, which allowed the flame to be maintained. In the biological analogy, inspired air brought no new material to the innate heat, whose substrate was blood. As with the flame, the air produced movement and cooling needed to keep the innate heat in good order. Its action was only dynamic and qualitative. Expiration, for its part, expelled residues of combustion which allowed the flame or the innate heat to renew itself. Galen confessed, however, that he did not really understand why flames or living things die so quickly on being deprived of air [6]. He thought inspired air, or pneuma, permeated the wall of the pulmonary vein, mingled with blood and went into the left ventricle. There it met newly formed blood from the liver, that had crossed through the interventricular septum. From the left ventricle some blood charged with vital spirit went to the brain, where it was changed to animal spirit responsible for sensory and motor functions, but the majority was distributed to the rest of the body through arteries filled with pneumatized blood. Galen had modified Erasistratus's theory substantially by proving the arteries contained blood rather than air [7, 8].

Galen's most important books on respiration "On the Causes of Respiration" and "On the Movements of the Thorax and Lung" have been lost. A few short fragments remain, however, and Galen refers to the works in some of his other writings, so that we know what they contained. "On the Movement of the Thorax and Lungs" recorded previous work of Erasistratus and his followers showing that the chest wall moves passive lungs and something about the nature of chest wall movement. "The Causes of Respiration" describes Galen's original findings about chest wall movement, including the discovery of two layers of intercostal muscles and the enumeration of all respiratory muscles with demonstration of their innervation.

Many of the important experiments and observations from these works are mentioned or summarised in "Anatomical Procedures", (De Anatomicis Administrationibus), apparently a verbatim record of a series of lecture-demonstrations in which Galen describes how to perform both detailed dissections and experiments on living animals. Here we get the flavour of the man and of his methods, and a clear picture of his achievements. Like a modern scientist, he makes frequent reference to the literature, giving credit to admired predecessors or taking issue with rival opinions. He hectors his students to work hard, shows them how to perform difficult manoeuvres, offers some of his personal philosophy, demonstrates his love of the subject, and insists on the originality and importance of his own discoveries [9].

To reveal the diaphragm, Galen makes it clear that it is necessary to perform two dissections, one from above through an opening in the thorax, and one from below, through the abdominal wall with removal of the viscera. $\mathrm{He}$ describes in detail the pleural and peritoneal membranes on either side of the diaphragm, the origins on ribs, spine and arcuate ligaments, the crura, the central tendon and the apertures (known to Hippocrates) for the aorta, oesophagus and vena cava [10].

Book VIII of "Anatomical Procedures" describes in minute detail how to perform a remarkable series of experiments by which Galen demonstrated the anatomy and the functions of the respiratory muscles. In chapter 3 , he describes how to cut the intercostal muscles, one layer at a time, beginning on dead animals and developing the skill until it could be used on live animals [11]. He explains exactly how to perform an experiment in 
which all the external intercostals are cut through, leaving intact the nerves, arteries, internal intercostals and pleural membrane. Regrettably, he does not describe the result, merely referring the listener to his other books, now lost.

For many of his experiments, he chose a large pig with a strong voice, and used the loudness of its cries to monitor activity of the organs that generate voice and respiration. Galen says that he was the first to use this preparation, which made it easy for a large audience to follow the demonstration. Adherents of the Helsinki Convention, appalled by the idea of these vivisections, must remember that our collective conscience is an historical novelty. Before anaesthetics, the desire to advance biological knowledge came into sharper conflict with the need to be kind to animals than it does today. Some scientists did recoil from operations on conscious animals [12], but physiologists from Vesalius's time to the end of the 19th century performed experiments like Galen's without recorded compunction, perhaps secure in the belief that the humbler species are not sentient in the same way as humans. The censorious may be mollified to learn that Galen avoided experimenting on monkeys because the spectacle was too hideous [13]. His gladiators, after all, had hardly been better treated.

Using the live pig, he begins with experiments known to his predecessors: "When a considerable incision is made anywhere between the ribs and through the pleural membrane lining them, the animal at once loses half its power of respiration and phonation. If a similar cut be made on the other side of the thorax, it ceases to breathe or cry. But when the thorax is contracted and the air that has got in through the incisions has been emptied out, if you then block the incisions, the animal will at once breathe and utter a cry. It is easy to block them by drawing together the lips of the incisions, using the hand that is holding them together as a cover for the part that is not blocked" [14].

In Chapter 4, he goes on to experiments of his own devising, where the intercostal muscles are eliminated either by cutting through them, as described before, or by paralysing them. The latter was done by dissecting the intercostal space close to the spine (he describes the technique and the best instruments for this) and tying threads tightly around the nerves. With several assistants and just the right kind of threads and knots, he could produce a quick block of all the intercostal nerves and then reverse it by letting the tension off the threads. Interfering with these nerves, he found, suppressed not only the voice but also the power of expiration [15].

To demonstrate the action of the diaphragm, Galen performed a series of spinal cord sections and muscle denervations: "I perform this experiment on the spinal cord, as you know, in larger animals by excising first the arches of the vertebrae, but in small animals, like young pigs of a few days old, by an instrument of my own devising, the so-called sharp-pointed bistoury (a kind of scalpel). It should be made of the finest steel, like the Notican, that it be not blunted, bent or broken. It must be thicker than a common bistoury, so that, as you press on the junction of the vertebrae, the operation is accomplished with ease. Sometimes, as you know, after piercing the skin and underlying tissues with the scalpel, I insert the "elongated knife", for so I call it (with its sharp edges meeting at the end in a single point), as far as the joints of the vertebrae. Sometimes too, I excise beforehand the posterior apophyses or the whole convex part at the back of the vertebrae themselves. Often also, I remove as much of the spinal muscles as lies between the middle of the spine and the ends of these oblique apophyses (transverse processes) to get an accurate view of the vertebral joints. I think it right to notice particularly the processes of the spine. They run slightly downwards, so that the first stroke of the scalpel should be made rather slantwise down from above, and the second precisely at right angles" [16].

When a spinal section was performed between the 7 th and 8th cervical vertebrae: "the parts below, i.e. the intercostal and abdominal muscles, are also paralysed. Along with them, the muscles in fundament, penis, bladder, and legs are also paralysed. The diaphragm, however, though lower than the intercostals, is not paralysed, because the origin of its nerves is above the thorax. Nor is there damage to the six muscles descending from the neck which dilate the thorax and particularly its upper part, for they too have their nerves from the spinal cord in the neck".

"You have seen all this publicly demonstrated when the thorax was the subject for dissection. I had to explain and demonstrate its nature during many consecutive days. When the spinal cord was severed at the beginning of the thorax, which is between the 7th and 8th vertebrae, the animal fell and lay on its side, the lower parts of the thorax being moved by the diaphragm alone, which an animal uses for shallow breathing only. When, however, it needs to fetch deeper breaths, whether by reason of exhaustion, or fever, or because of the heat, or for some bodily distress, it must invoke the intercostals to the aid of the diaphragm and, at need, the higher (neck accessory) muscles as well".

"You observed the animal, when the spinal cord was severed at the beginning of the back, falling down at once, lying on its side, remaining dumb, and its thorax devoid of movement, except below where it is moved by the action of the diaphragm. Also, you observed that the movement of the parts of the thorax is more clearly seen when all the surrounding skin has been removed. All the intercostal muscles became completely motionless, while the lower parts of the thorax were dilating, some faint movement passing to the upper parts. So with the animal in this condition, as you know, I again cut the origins of the nerves descending into the diaphragm. Immediately the movement of the lower thorax ceased and the high muscles were forced into action, and the upper region of the thorax was clearly seen being dilated by them".

"Taking a second animal and cutting the cervical nerveroots to the diaphragm, I immobilised the lower thorax at once while the intercostals remained active. When the cord was cut at the beginning of the back, you will remember that the animal at once lay on its side, moving both parts of the thorax, the higher and lower but 
not the middle for, because of the need to inhale more deeply, the diaphragm alone did not suffice. When, however, the animal inhales with the aid of the upper muscles, the movement is plainly visible along the entire shoulder-blades as far as the top of the shoulder. But when it breathes with the diaphragm alone, the hypochondria swell at each inhalation and contract at each exhalation, the parts at the shoulder-blades remaining motionless. When only the intercostals are called into play, the shoulder-blades are motionless, but the hypochondria contract as the animals inhale and swell as they exhale, the reverse of what happens when the diaphragm is active" [17].

It is noteworthy that Galen's conclusions about the action of the diaphragm on the chest wall are almost exactly the same as the ones reached by studying human quadriplegics with modern techniques [18]. In fact, an up-to-date physiologist of 1994 would find nothing to disagree with in the entire description just quoted.

Later chapters in "On Anatomical Procedures" describe the section of the cervical respiratory muscles, the details of dissection of the phrenic nerve, and the method of observing lung movement in living animals by looking through the transparent parietal pleura or diaphragm.

In "De Motu Musclorum" (On the Motion of Muscles) he considered whether quiet expiration was controlled passively or actively, using for analogy the process of allowing an uplifted arm to fall back down compared to lowering it gently into place. He decided in favour of completely passive expiration [5]. This was apparently not a complete account of his view, however, because the diaphragm is listed as being used in some circumstances in quiet expiration in "De Causis Respirationis" [19], a very brief summary of the lost book. We can only guess whether Galen was thinking here of some expiratory effect of diaphragm contraction or of an inspiratory braking action in expiration.

In all of his studies of respiratory muscles, Galen was clear about the function of a muscle per se. In other experiments and arguments, he showed conclusively that muscles were the major sources of movement, that they generated force in the direction of their fibres by contracting while thickening, that they could not actively extend themselves, and that they were disabled by cutting their nerves or their attachments [20].

"On the Usefulness of the Parts" is a comprehensive summary of anatomy and physiology, whose object is to show how Nature has marvellously constructed each part of the body to suit its function [21]. This is pure Aristotelian teleology, the later refinements of which were ridiculed by Voltaire (Candide learned that we wear spectacles because the nose is perfectly suited for them). Modern physiologists profess to find the principle fallacious, although much of modern research arises from a fruitful tendency to believe that if things are the way they are there must be some good in it. The difference is that speculative arguments in which evolution serves as the all-wise agent of Nature have now replaced the more mystical beliefs held by the Greeks.

Some of Galen's applications of the principle to diaphragm physiology show the possibilities, but also the limitations, of the teleological approach. He points out that a large part of the diaphragm lies along the inside of the rib cage, and wonders why. He concludes the arrangement allows the ribs to protect both liver and diaphragm from injury [22]. He then describes in detail the nerve supply of the diaphragm, from spinal roots $\mathrm{C} 3$ to C6 [23], and explains it: "In all muscles, ...the nerve ... is inserted into the heads of the muscle itself or at least into some part close under the head and certainly not beyond the middle of it. Nerves like those of the diaphragm that are inserted into the middle of the muscle and distributed from that point to all parts of it draw all the fibres toward the centre, thus making the centre the head of the muscle" [24]. Since the purpose of the diaphragm is to move the rib cage, the insertion is on the ribs, and the "head" (or origin as we would say) must be at its centre. It is, thus, essential for the nerve to run to the centre rather than the periphery of the diaphragm. This explains why Nature used the curious arrangement of phrenic nerves descending the length of the thorax. Furthermore, the choice of $\mathrm{C} 4,5$ and 6 for the origins of the phrenic nerve is ideal, because, firstly, with several segmental roots in several spaces the system is less vulnerable to injury. Secondly, whereas the nerve roots might come from higher up in the encephalon it is better that they arise from the spinal cord, which is made of a harder substance more suitable for controlling vigorous action. Finally, if they arose from lower than $\mathrm{C} 6$, the phrenic nerves would have to make a sharp bend in order to follow their course down along the mediastinum [25].

Later on, to explain how the arrangement of the diaphragm and the anterior abdominal wall are designed perfectly for the expulsion of faeces, Galen uses the analogy of a person squeezing water from a sponge with two hands [26]. The hands are held tightly together at the heels of the palms but are widely separated at the finger tips. As the hands are drawn together, water is squirted in the direction of the fingers. (A bar of soap would be shot out in the same way). The diaphragm and anterior abdominal wall are joined in a seam along the rib margin, like the heels of two hands, but are separated at their caudal insertions like the fingers. By contracting, the muscles apply a directional force to the abdominal contents, which are, thereby, ejected downwards. Nowadays, we would emphasize that muscle contraction changes abdominal pressure, equivalent to a force equal in all directions. Galen's explanation of expulsive efforts indicates that this concept was not understood by him and, in fact, was not available in his day.

Additional information about Galen's work on respiration comes through the great Alexandrian physician, Oribasius, who lived about 200 yrs after Galen's death. Oribasius was a friend and supporter of the Emperor Julian II (331-363AD), the Philosopher or the Apostate (depending on one's point of view). Exiled to Athens in his youth and brought up by philosophers, Julian repudiated Christianity, which had been made the state religion by his uncle Constantine, and returned to the old Roman gods. Unexpectedly made heir-apparent, he 
trained himself to be a general and statesman and was eventually killed while trying to recapture territory from the Persians. Throughout his reign, he persisted in his ascetic, intellectual habits, and did much to promote the arts and sciences. One of his achievements was to persuade Oribasius to set down his immense learning in a medical compendium.

Much of what Oribasius wrote about respiratory physiology can be found in the extant works of Galen, but he probably quotes as well from Galen's lost books "On the Movement of the Lungs and Thorax" and "On the Cause of Respiration". If in reading Galen we are brought into close contact with a great experimental physiologist publishing his research and defending it, as would be done today, in Oribasius we encounter instead a great writer of textbooks for students. He summarizes clearly the ideas found in Galen, preserving the essence without waste of words. Difficult concepts get longer explanations helped by examples and similes. He expounds at some length the problem of how the lungs, supposed to be passive, could be expanded by a chest wall which is not attached to them: "We have shown that the lung makes no movements on its own, but that it always needs the chest wall to move it. That is, it is not possible to find a situation where the lung is seen to move while the chest wall is stationary. On the other hand, although motion of the lung always disappears as soon as the chest wall stops moving, motion of the chest wall does not (necessarily) disappear when the lung stops moving. It is therefore not unreasonable to admit that the chest wall governs movement of the lung but has no need of the lung in order to move itself. But the fact that there is no connection or attachment by means of which the chest wall can draw the lung open when it dilates ... makes the cause of movement of the lung difficult to understand. Let us see, however, if we can explain a cause for the dilatation of the lung. When the chest wall dilates, the lung must move with it, because it is drawn open by virtue of the need to replace material which is evacuated. Material that is evacuated is always replaced by neighbouring material, as is clear for little tubes dipped in water: if you suck air from the tube with your mouth, you draw up water which can rise to a great height against its natural tendency. Such is the degree of violence which accompanies the replacement of a void. And if there were another body more proper than the lung to fill the gap between the organs, the lung would stay immobile, as happens with wide open chest wounds. In this case one sees plainly that air from outside is drawn into the empty space in the chest, because due to its lightness it is easier to draw in than the lung. Since this air has already occupied the void formed by dilating the thorax, it follows that the lung must rest immobile. How could it move when the cause for its movement has disappeared? Because this cause was the absence of any other body that could move into the space between lung and chest wall. Such, therefore, is the movement of these organs, and the chest wall governs the movement of the lung" [27].

Summarizing statements from "On the Usefulness of the Parts of the Body", Oribasius also explains the concept of interaction between the abdominal and rib cage muscles in maintaining the position of the diaphragm: "during forced expiration, when the 28 muscles that contract the chest wall act with violence, the lung, strongly compressed on two sides by the walls of the rib cage as if by two large hands, is pushed towards the point which gives way and is thus forced down onto the diaphragm in such a way as to push that muscle and, with it, all the abdominal contents out into the hypochondrium. Nature, coming to the assistance of the diaphragm in order to keep that from happening, has thus constructed the muscles of the hypochondrium like a second pair of hands which hold the diaphragm anteriorly and inferiorly during strong contractions of the intercostals: for this reason, we tense not only the intercostals but also the hypochondrial muscles when we wish to produce a sudden exhalation, not because they sustain the diaphragm whose action would weaken if it was not supported, but because during exhalation the lung not only must be compressed by the thorax but must also be held up from underneath, so that the compression is as far as possible equal on all sides" [28].

Finally, Oribasius reviews how the diaphragm and the abdominal muscles contract together to expel faeces or urine, and points out that the diaphragm, although very effective for the purpose, is just one muscle contending against numerous abdominal muscles and is, therefore, in danger of being forced up into the thorax. It is because of this, he explains, that the expiratory intercostals contract during defaecation to assist the diaphragm to balance the powerful abdominal muscles. The much lengthier text from which he is quoting [26] shows a clear understanding of the principle that the diaphragm can move upward during an isovolume manoeuvre, as long as the rib cage is allowed to expand.

As well as a great scientist, Galen was a skilful and innovative clinician who applied what he learned about the diaphragm to the analysis of problems at the bedside. He taught physicians to observe motion of the chest wall to see which respiratory muscles were in use, and analysed dyspnoea according to a logic that began with observing which muscles were being used [29, 30]. If the intercostal and neck accessories were active, he reasoned that either the innate heat was overactive (fever or exercise), or the airways were obstructed, or some of the respiratory muscles were weak. He considered that dyspnoea could result when the diaphragm is either pulled downwards or put under pressure. Among his detailed clinical histories is one about an athlete named Secundus, with a weak diaphragm, whose breathing he improved by putting a girdle around the hypochondrium, and one about a man who lost the function of his diaphragm after being kicked in the abdomen by a horse [29].

$\mathrm{He}$ also discusses at some length the old theme of a link between the diaphragm and the brain in "On the Parts Affected", where he classifies delirium or phrenitis into two general types. One type arises primarily in the brain, but the other is a sympathetic reaction to disease or irritation in the region of the diaphragm. The two can sometimes be distinguished by the pattern of breathing [31]. 
Although Galen's respiratory investigations may resemble modern work to an astonishing degree, he was not, of course, a modern physiologist. He had not been provided with the concepts of physics, such as pressure, volume, flow, tension and force, that are fundamental to current analysis of muscle mechanics. He asked somewhat different sorts of questions from our current ones: his demonstrations showed very clearly what the diaphragm did but not how it did it, a deficiency for which he was to be reproached 1,200 yrs later by Vesalius, who lived in an age of engineers.

Galen's work was hampered by other historical circumstances. Lack of a good nomenclature was a real limitation to the powers of anatomical description. Barriers to performance of human autopsies prevented clinicopathological studies. Physiology experiments were conducted on species not very closely related to man (a limitation the modern respiratory muscle physiologist would readily accept). Ideas of measurement and quantification in biological studies were so rudimentary throughout antiquity that the introduction of measuring devices is considered a major feature of the revolution in biological thinking at the time of the Renaissance [32]. Galen did use some quantitative reasoning and was skilled in mathematics, but the main emphasis was on proportions rather than absolute values [5]. Thus, he cut a half or three quarters of the expiratory intercostal muscles of a pig, and noted that the loudness of the animal's cries was reduced by a half or three quarters.

An important quantitative question of the day was whether respiration required the consumption of air. Much learned comment has been attracted by Galen's description of an experiment in which a subject breathed from a bag sealed around the face. He said there was no change in bag volume or in the condition of the subject over some hours, and concluded that vital combustion did not consume significant amounts of air. Anyone who has taken part in rebreathing experiments will find it difficult to believe the truth of this report. Perhaps it was a "thought experiment", of whose hypothetical results he was too certain. His conclusion was more realistically supported by breath holding experiments, during which the ancients were unable to perceive any loss of lung volume [33]. Following concepts from Aristotle's physics, Galen deduced that since air was not absorbed quantitatively, there was a peculiar quality of the pneuma that was absorbed by the body in the process of respiration: "it is not the substance but some quality of air which is required by the heart" [34]. In an addendum to this discussion, however, he noted the possibility that air could be consumed and then replaced by fumes. These arguments closely paralleled the sequence of experiments and the logic that led Mayow, in the 17th century, to the conclusion that respiration and combustion were alike [12]. Using similar methods to investigate whether air could get into the pleural space from the lungs, Galen sealed the mouth of the bag to a circular area where the skin had been excised over the rib cage, then with a scalpel in an airtight sleeve through the bag made an incision through the intercostal space and parietal pleura, not damaging the underlying lung. This allowed him to watch the bag filling and emptying with respiration to see if there was any steady accumulation of volume over time. All these experiments, however, lacked precise measurements of quantity of gas, just as his respiratory muscle experiments lacked quantitative measurements of expansion by length, circumference or volume, of force or pressure, or even of respiratory rate.

Any concept of statistics is also missing. There is no question that Galen was very conscious of the problem of uncertainty of observations in medicine and therapeutics, as shown by the details he gave of the diagnosis of depression in a young woman who, it turned out, was pining for the affections of a certain actor. He made repeated observations over several days on the behaviour of her pulse when the actor's name was mentioned, and controlled the experiment by introducing the names of other actors [1]. But, in the accounts we have of his physiology experiments, phrases like "I cut this nerve, and you see the result" take the place of ones like "the data tend to suggest" that modern physiologists use to show their heightened consciousness of possible error.

In the second century $\mathrm{AD}$, there were no scientific journals, but at the same time no formidable editors and referees to interfere with publication. To keep his reputation from perishing, Galen was obliged to proclaim his results through repeated public demonstrations, and to defend his theories in debates against the many vigorous contending sects who accepted neither his conclusions nor the theory of knowledge and evidence that led to them. The attacks of his rivals may have limited his vision to some extent, and the need to make a convincing public show may have governed his choice of fields for investigation [5]. It is quite possible that the need to broadcast his work and establish his reputation had as much influence on Galen's career as it does for modern researchers.

What he had to contend with was shown by a public debate with a prestigious philosopher, Alexander of Damas. When Galen demonstrated the function of the laryngeal nerves by dissecting them out and cutting them, his opponent denied the validity of his proof on the ground that the evidence of the senses was not reliable. Galen's account of this frustrating episode finished with an unscholarly assessment of Alexander's character and intelligence. Another example is Oribasius's argument that the chest wall moves the lung. Striking in its forcefulness, the passage suggests that in his day, as in Galen's, the concept was not widely accepted. Many scholars preferred the authority of Aristotle's view from $400 \mathrm{yrs}$ earlier that the heart imparts motion to the lungs, which then expand and force the chest to follow them.

The extent of his original and lasting contributions to respiratory pump physiology leaves no doubt that Galen stood far above his contemporaries. He identified all the important respiratory muscles, including those of the larynx, and discovered and described the motor innervation of each one. Using this information as a blueprint, he conducted an extensive and systematic series of ablation experiments, that showed amongst other things what happens when the diaphragm is paralysed, and, 
on the other hand, what happens when all the other respiratory muscles are disabled, leaving the diaphragm to contract alone. He used semiquantitative measurements of respiratory output to estimate the contribution of various muscles to respiration and voice production. He greatly clarified the description and analysis of all these experiments by introducing a classification of breathing movements that separated inspiration from expiration and quiet respiration from forced respiration. He applied knowledge from dissections and vivisection to the analysis of bedside problems in respiratory disease and observations on normal human subjects. The assembly of all his conclusions gives a rather complete view of diaphragm action that is very close to the modern one.

Galen exhorted his students to perform dissections and experiments on living animals in order to see the facts for themselves, rather than rely on written descriptions open to misinterpretation. His own example and teaching emphasized that biological concepts need to be verified by observation, and can be challenged and modified. Regrettably, however, this whole tradition handed down from Erasistratus died out soon after Galen's death. His remarkable work on the diaphragm was not quoted again in any detail until the 18th century, and the experiments themselves were regularly forgotten and repeated in one form or another. In the 17th century the Oxford physiologists, Highmore and Boyle, induced pneumothoraxes to show the lungs were passive [12]. The muscle investigations were performed in the 19th century by BEAU and Maissiat [36], Bert [37] and Duchenne de Boulogne [38] and again in the last part of this century. (See [39] for a summary of recent work).

Although Oribasius can be seen as passing on many of Galen's conclusions intact, his works foretell what the authors of following centuries were to become: guardians of endangered knowledge rather than creators of new intellectual goods. Throughout the Middle Ages, there would be a gradual degradation and disappearance of this knowledge, requiring its near total rediscovery, beginning in the Renaissance.

Acknowledgement: The authors are much indebted to J. Whitelaw for numerous editorial suggestions.

\section{References}

1. Moraux P. Galien de Pergame. Les Belles Lettres. Paris, 1985.

2. Temkin O. Galenism. Rise and decline of a medical philosophy. Ithaca, Cornell University Press, 1973.

3. Galen. On Anatomical Procedures (De Anatomicis Administrationibus). Introduction by C. Singer. London, Oxford University Press, 1956.

4. Andre J. Etre médecin à Rome. Les Belles Lettres. Paris, 1987.

5. Debru A. La pensée physiologique. Doctrines et langages de la respiration chez Galien dans le monde greco-romain. Paris, Thèse, 1990.

6. Furley DJ, Wilkie JS. Galen on respiration and the arteries. Princeton, Princeton University Press, 1989.

7. Siegel RE. Galen's System of Physiology and Medicine. Basel, S. Karger, 1968.
8. Galen. On Anatomical Procedures (De Anatomicus Administrationibus). Book VII, Chap. 16, pp. 642-650, Kuhn. Translated with an introduction and notes by C. Singer. London, Oxford University Press, 1956.

9. Ibid. Book V, Chap. 2, p. 660, Kuhn.

10. Ibid. Book V, Chap. 5 and 8.

11. Ibid. Book VIII, Chap. 3, pp. 661-664, Kuhn.

12. Frank RG Jr. Harvey and the Oxford Physiologists. Berkeley, University of California Press, 1980.

13. Galen. On Anatomical Procedures (De Anatomicis Administrationibus). Book VIII, Chap. 8, p. 690, Kuhn. Translated with an introduction and notes by C. Singer. London, Oxford University Press, 1956.

14. Ibid. Book VIII, Chap. 3, pp. 665, Kuhn

15. Ibid. Book VIII, Chap. 4, pp. 667-675, Kuhn.

16. Ibid. Book VIII, Chap. 6, pp. 681-683, Kuhn.

17. Ibid. Book VIII, Chap. 5, pp. 676-679, Kuhn.

18. Estenne M, De Troyer A. Relationship between respiratory muscle electromyogram and rib cage motion in tetraplegia. Am Rev Respir Dis 1985; 132: 53-59.

19. Galen. On the Causes of Breathing (De Causis Respirationis). In: Galen on respiration and the arteries. Translations by D.J. Furley and J.S. Wilkie. Princeton, Princeton University Press, 1989.

20. Bastholm E. The History of Muscle Physiology. Copenhagen, E. Munksgaard, 1950.

21. Galen. On the Usefulness of the Parts of the Body (De Usu Partium). Book V, Chap. 15. Translated from the Greek with an introduction and commentary by M.T. May. Ithaca, Cornell University Press, 1968.

22. Ibid. Book VII, Chap. 21.

23. Ibid. Book XIII, Chap. 5.

24. Ibid. Book VII, Chap. 14.

25. Ibid. Book XIII, Chap. 9.

26. Ibid. Book V, Chap. 15.

27. Oribasius. Oeuvres d'Oribase. Traduit par C. Daremberg et E. Busemaker. Paris, Imprimerie Impériale, 1851-1876. English translations by W.A. Whitelaw. Chap. 42 of an unnumbered book "Motion of the Lungs and Thorax".

28. Ibid. Chap. 43, of an unnumbered book "The Cause of Respiration".

29. Galen. On the Affected Parts (De Locis Affectis). Translated by R.F. Siegel. Basel, S. Karger, 1976; Book IV, Chapter 7.

30. Ibid. Book IV, Chap. 10.

31. Ibid. Book V, Chap. 4.

32. Grmek MD. La première révolution biologique. Paris, Payot, 1990.

33. Galen. On the Usefulness of Breathing (De usu respirationis). Book V, Chap. 9. In: Galen on respiration and the arteries. Translations by D.J. Furley and J.S. Wilkie. Princeton, Princeton University Press, 1989.

34. Ibid. Book V, Chap. 9, (Kuhn IV, 511).

35. Galen. On Anatomical Procedures (De Anatomicus Administrationibus). Book VIII, Ch. 10, 703-704, Kuhn.

36. Beau JHS, Maissiat JH. Recherche sur le mécanisme des mouvements respiratoires. Arch Gen Med 1843; 4ème série I: 265-295.

37. Bert P. Leçon sur la physique comparée de la respiration. Paris, J.B. Baillière et fils, 1870.

38. Duchenne de Boulogne GBA. Recherches électrophysiologiques, pathologiques et thérapeutiques sur le diaphragme. Paris, Félix Matteste, 1853.

39. De Troyer A. Respiratory muscle action. In: Handbook of Physiology. Section 3, Vol. III. Mechanics of Breathing. Part 2. Macklem PT, Mead J, eds. Bethesda, American Physiological Society, 1986. 